\title{
Effects of Enforcement of Youth Access Laws on Smoking Prevalence ${ }^{1}$
}

\author{
Leonard A. Jason ${ }^{2}$ \\ DePaul University \\ Marjorie Berk \\ University of Michigan \\ Daniel L. Schnopp-Wyatt \\ American Lung Association of Metropolitan Chicago \\ Bruce Talbot \\ Woodridge Police Department
}

\begin{abstract}
Smoking is the primary preventable cause of death, and yet 3,000 adolescents become smokers each day. Most adult smokers begin this deadly habit when they are under the age of 18, which is the minimum legal age for the purchase of cigarettes. The majority of adolescent smokers are able to purchase cigarettes even though laws prohibit the sale of cigarettes to minors. In the late 1980s, Woodridge, IL, became one of the first towns in the nation to demonstrate a significant reduction in the ability of youth to purchase cigarettes. Almost 2 years after passage of this legislation, the percentage of regular smokers among 7th-and 8th-grade students had been reduced from 16 to 5\%. Seven-year follow-up data in a sample of high school youths indicate that youths living in communities with regular enforcement had significantly less smoking than those living in communities without regular enforcement. In particular, rates of regular smoking were $8.1 \%$ in communities with regular enforcement versus $15.5 \%$ in communities without regular

${ }^{1}$ The authors appreciate the support and help Gretchen Sauer, at Downers Grove South High School, and Officer Ed Krause, for their help in conducting this study.

${ }^{2}$ All correspondence should be sent to Leonard A. Jason, Department of Psychology, DePaul University, Chicago, Illinois 60614.
\end{abstract}


enforcement. It is possible that adolescents who had restricted access to tobacco products were less likely to become regular smokers. These findings have important public health implications, particularly in light of recent federal legislation mandating that all states develop programs to reduce access of youth to tobacco products.

KEY WORDS: minors access to tobacco; youth access laws; smoking prevention; vendor assessment; possession enforcement.

Researchers have long grappled with the problem of reducing tobacco use as a way optimizing the health and well-being of communities (Rhodes \& Jason, 1988). Every day, 3,000 American adolescents begin smoking (Pierce, Fiore, Novotny, Hatziandreu, \& Davis, 1989), and it is estimated that 1,000 of these children will eventually die of tobacco-related illness. Smoking is the leading preventable cause of death in the United States, killing over 400,000 people each year (Centers for Disease Control [CDC], 1993). This is more people than die each year of acquired immune deficiency syndrome, homicide, suicide, automobile accidents, illegal drug use, and fires combined (Department of Health and Human Services, 1995). The direct medical costs of treating tobacco-related disease in the United States are estimated at $\$ 50$ billion per year (CDC, 1996). The amount of human pain and suffering caused by tobacco use is unmeasurable. Despite these facts, $22.9 \%$ of adult Americans and $13.8 \%$ of Americans under the age of 18 smoke cigarettes (CDC, 1996).

Nicotine addiction typically begins in adolescence with experimental cigarette smoking that progresses to smoking as a social activity and finally to regular, daily cigarette smoking (Johnston, O'Malley, \& Bachman, 1994). One of the antecedents to adolescent cigarette smoking is easy access to tobacco products (DiFranza, Carlson, \& Caisse, 1992; Jason, Ji, Anes, \& Birkhead, 1991; Stanton, Mahalski, McGee, \& Silva, 1993). It is reported that in most areas minors can purchase cigarettes from retailers most of the time (Billows et al., 1995; Forster, Komro, \& Wolfson, 1996; Jason, Ji, \& Anes, 1992; Jason, Billows, Schnopp-Wyatt, \& King, 1996b; Johnston et al., 1994; Radecki \& Zdunich, 1993).

Educational programs have been implemented as a preventive measure, but it seems that cigarette sales remain unchanged or rebound after time (Altman, Rasenick-Douss, Foster, \& Tye, 1991; Biglan et al., 1995; A. Biglan, personal communication, September 26, 1995; "Reducing Minor's Access," 1990). In addition, Feighery, Altman, and Shaffer (1991) found that the majority of judges who conducted merchant cigarette violation hearings either suspended the sentences or waived the fine.

In a collaborative study designed by the first author, baseline data from the police and concerned politicians in Woodridge, IL, indicated that approximately $70 \%$ of stores sold cigarettes to minors. Community antismoking 
legislation was developed that involved licensing and enforcement. During the enforcement condition, minors went into the stores on a regular basis and police reported merchants who sold cigarettes to the Woodridge mayor, who is the village liquor and tobacco commissioner. The mayor issued fines and suspended the tobacco license of merchants who were found in an administrative hearing to have violated the age restrictions on tobacco sales (Jason et al., 1991). After enforcement began, cigarette sales dropped to less than 5\%. Follow-up data with older minors, ages 15-17 years, showed that sales remained at low levels (below $20 \%$, except for one sample when the sales rate was 25\%) (Jason et al., 1996). Student surveys conducted 2 years after passage of this legislation indicated that rates of regular smoking among seventh and eighth graders had been reduced from $16 \%$ to $5 \%$.

Successful laws have several common characteristics. These characteristics are (a) civil, not criminal, penalties that are leveled against the store owner and not just against the clerk, (b) progressively increasing fees culminating in the suspension or revocation of a tobacco vendors license, and (c) regular enforcement of the law using minors in unannounced purchase attempts to monitor compliance. As mentioned above, the village of Woodridge was the first documented case of a community that, using a law that had these three characteristics, was able to reduce the sales rate of tobacco to minors (Jason et al., 1991). In Bolingbrook, IL, a town next to Woodridge, quarterly compliance checks have also successfully lowered illegal cigarette sales (Radecki \& Strohl, 1991). Studies have shown that reductions in youth's ability to purchase tobacco can be achieved through regular enforcement of these types of youth access-to-tobacco laws (Jason, Billows, Schnopp-Wyatt, \& King, 1996a, 1996b; Johnston et al., 1994).

Efforts such as those described above will soon become common due to recent federal legislation. In 1996, the Department of Health and Human Services (DHHS) finalized and published the Substance Abuse and Mental Health Services Administration (SAMHSA) regulation implementing the Synar Amendment. The key requirements of the regulation require states to (a) adopt laws prohibiting the sale of tobacco to any individual under the age of 18; (b) enforce such laws in a manner that can reasonably be expected to reduce the extent to which tobacco products are available to minors; (c) conduct annual random, unannounced inspections to ensure compliance with the law; (d) develop a strategy and time frame for reducing illegal cigarette sales to less than 20\%; and (e) and submit an annual report, detailing efforts to enforce the law, which describes how inspections were conducted, the methods of identifying tobacco outlets, and the overall success of the previous fiscal year to reduce minors' access to tobacco. In addition, the report must also include plans for enforcing the law in the coming fiscal year. The Synar Amendment also requires the federal govern- 
ment to deduct $10 \%$ of substance abuse funds from states which do not comply with the regulations in the 1st year, $20 \%$ in the 2 nd year, $30 \%$ in the 3 rd year, and $40 \%$ for noncompliance in the 4 th and all subsequent years.

An important public health question that arises is whether this reduction of minors' ability to purchase tobacco has any effect on the level of cigarette smoking among youths. Earlier work on the smoking rates in the Woodridge area found that the smoking rate of seventh and eighth graders decreased considerably after 2 years of enforcement using compliance checks (Jason et al., 1991). A study conducted in Massachusetts found a $38 \%$ decrease in the smoking rate of 13- to 17-year-olds (DiFranza et al., 1992) and a study conducted in Washington found a $22 \%$ decrease in the adolescent smoking rate with in a year of the initiation of compliance checks (Hinds, 1992). None of these studies, unfortunately, used comparison groups or provided longer term follow-up data. A more controlled study by Rigotti et al. (1997) found that enforcement in three communities, when compared to three control communities, did not lead to reductions in youth tobacco use; however, self-reported access to tobacco remained at high levels in both experimental and control communities.

The current study sought to examine the smoking habits of high school students in Woodridge and the surrounding communities of Downers Grove, Darien, Westmont, and Bolingbrook. At the time of this survey two of the communities, Woodridge and Bolingbrook were regularly enforcing youth access to tobacco laws. Children from these communities attend the same high school, allowing for the collection of survey data from each community by a single round of survey dissemination. Primary categories that were compared are the two communities that had regular enforcement versus the three that did not. In addition, there was a comparision between adolescents from Woodridge versus Downers Grove, because they are the largest samples, and one of these communities had regular enforcement and the other did not. It was hypothesized that lower smoking prevalence rates would be found in communities with regular enforcement than in communities without regular enforcement.

\section{METHOD}

\section{Study Site}

Woodridge

Woodridge is a village of approximately 26,000 inhabitants, who are $86 \%$ White, $6 \%$ African American, $6 \%$ Asian American, and $1 \%$ other, and 
the average income is approximately $\$ 44,500$ (1990 U.S. Census). Illegal cigarette sales data for the village of Woodridge have been collected continually since August of 1988. Quarterly compliance checks of all licenced tobacco retailers (which range from 25 to 30 ) in Woodridge were conducted by the Woodridge Police Department. In a previous study mentioned above, Jason et al. (1991) had collected data from August 1988 until December 1990. Sales of cigarettes to 12- and 13-year-old minors had been reduced from a baseline of $70 \%$ before the legislation to less than $5 \%$ after compliance checking occurred. In the follow-up study by Jason et al. (1996a), older minors were used during data collection points from January 1991 until December 1994. A 16-year-old was used in the final two sessions, and illegal cigarette sales were 7 and $11 \%$.

All purchase attempts are observed unobtrusively by a Woodridge police officer dressed in civilian clothing. Since March 1989, when an ordinance was passed, if cigarettes are sold to the minor, the police officer would approach the merchant and issue a report. Reports are processed by the mayor's office and all merchants are given the opportunity to appeal in civil court. If the sale is the merchant's first offense, a warning is issued. Second offenses are subject to monetary fines of up to $\$ 500$ and/or license suspension. The severity of the penalty is increased for each subsequent offense, with the possibility of license revocation. In addition, if minors are observed by police officers smoking or in possession of tobacco, they are given a $\$ 25$ parking-style ticket and the tobacco is confiscated. The issuing police officer is required to notify the minor's parent of the police intervention.

\section{Other Communities}

Downers Grove, Westmont, Darien, and Bolingbrook are communities in the same region as Woodridge, and all four towns send their students to South High School in Downers Grove. These communities are primarily in DuPage County (with the exception that Woodridge has a small section in Will County, and Bolingbrook is also partially located in Will County). These are generally middle to upper income communities. DuPage county has an annual median household income of $\$ 48,900$, and $92 \%$ of its residents are White, 2\% African American, 5\% Asian American, and 1\% other. According to the 1990 U.S. Census, there are approximately 46,900; 21,200; 18,300 ; and 40,800 residents, with median household incomes of $\$ 48,200$; $\$ 37,300 ; \$ 52,900$; and $\$ 51,700$ in Downers Grove, Westmont, Darien, and Bolingbrook, respectively. The ethnic composition of Downers Grove is 93\% White, 2\% African American, 4\% Asian American, and 1\% other; for 
Westmont, $87 \%$ White, 3\% African American, 9\% Asian American, and 1\% other; for Darien, 89\% White, 1\% African American, 9\% Asian American, and $1 \%$ other; and for Bolingbrook, $76 \%$ White, $16 \%$ African American, 5\% Asian American, and 3\% other.

Bolingbrook is the only other town with a licensing law that has been regularly conducting enforcements with 16- and 17-year-olds (Radecki \& Zdunich, 1993). This law which was enacted in August of 1989, provides merchants a warning for a first violation, and if a second offense occurs during the next 2 years, the Mayor provides a fine and possible license suspension, which is based on the Mayor's discretion. In addition, minors are given tickets for possession of cigarettes.

There has never been any enforcement of Darien's license law which was enacted in December 1989. The school resource officer assigned to the Claredon Hills High School, which is located in Darien, does issue tickets for students smoking on and around school grounds. Westmont had passed a licensing ordinance in June 1996, after the survey described in this study had been administered. No enforcements had occurred in Westmont prior to the survey being distributed. Downers Grove does not have a license law. During the year prior to the study, the police in Downers Grove did some enforcements of several gas stations next to the high school, and citations were given against the clerks who sold minors cigarettes, with a fine of $\$ 50$. In addition, if residents complained about youth smoking, the police issued citations to minors for possession, but this occurred only in the vicinity of the town's two high schools. In the Results section below, we refer to the enforcement communities as Woodridge and Bolingbrook, and the nonenforcement communities as Downers Grove, Westmont, and Darien. Even though some tickets were given in nonenforcement communities, and several merchants were fined, this was done on a reactive basis, and only in a few locations in the nonenforcement communities; whereas in the enforcement communities, enforcement occurred on a regular basis for all stores selling tobacco products.

\section{Downers Grove South High School}

There are approximately 3,000 ninth- through twelfth-grade students in this high school, with $46 \%$ from Downers Grove, $28 \%$ from Woodridge, $15 \%$ from Darien, $6 \%$ from Westmont, $4 \%$ from Bolingbrook, and $1 \%$ from Naperville (no students from Naperville were in our sample). We initially had hoped to have the questionnaire distributed to all tenth graders, but we were informed that this would not be possible. The school guidance 
counselor, with consent of school administrators, agreed to distribute the questionnaire in May of 1996 to approximately 300 students.

\section{Instrument}

Information was collected with a survey questionnaire. The questionnaires were distributed in randomly selected classrooms. No identifying information was collected; students were assured of the survey's confidentiality. A total of 357 students, 17 years old or younger, participated in the study. Students from five communities were represented in this study. These communities were Bolingbrook (15 students), Westmont (16), Darien (45), Woodridge (109), and Downers Grove (172).

Initial questions on the survey involved demographic variables, including age, year in school (sophomore, junior), gender, and town in which they resided. Students were next asked if they were aware of the smoking ordinance passed in Woodridge, as well as what sort of effect the ordinance had on them (i.e., prevent them from getting cigarettes, make it harder to get cigarettes, and have no effect of getting cigarettes). The students then classified themselves as to their smoking status (nonsmoker, experimental smoker, social smoker, regular/daily smoker), and reported whether they had ever tried chewing or other smokeless tobacco.

Those who had smoked were asked a series of additional questions such as their age when smoking their first cigarette, how often they smoked, where they obtained their cigarettes (stores, vending machines, parents, siblings, friends, etc.), and how easy or difficult it was to obtain cigarettes (using a 3-point scale, from easy to moderate to difficult).

The last series of questions dealt with illegal drug use. They were asked during the past 30 days, how often they used marijuana, alcohol, cocaine, illegal drugs, or inhalants. They were also asked how many of their friends smoked cigarettes or used other drugs, using a 5-point scale, ranging from 1 (none of them) to 5 (all of them). Finally, they were asked over the past year how many times a person had tried to give or sell them illegal drugs.

\section{RESULTS}

\section{Participant Demographics}

Demographic information on participants' age, school grade level, and gender was collected. The majority of the participants were 15 and 16 years old $(79 \%)$ and in Grade $10(65 \%)$. 
Table I presents demographic data. For all comparisons, significance was set at the .05 level. There were no significant age, school grade level, and gender differences between those communities with regular enforcement (Woodridge and Bolingbrook) versus those without regular enforcement (Downers Grove, Darien, Westmont): Age: $\chi^{2}(3, N=357)=0.92, p>$ .05 ; School grade level: $\chi^{2}(3, N=357)=0.46, p>.05$; Gender: $\chi^{2}(1$, $N=357)=1.44, p>.05$. When data from Woodridge and Downers Grove were compared, again there were no significant differences. In addition, when the five communities were compared, there were no significant differences on these three variables.

\section{Law Awareness}

The majority of the students in each community answered "yes" in response to the question "Are you aware of a law in the City of Woodridge that prohibits cigarette sales to minors?" On this variable, there was no significant difference between those communities with regular enforcement $(81 \%)$ versus those without regular enforcement $(78 \%), \chi^{2}(1, N=281)=$ $0.17, p>.05$. The percentage of students answering "yes" in Woodridge was $82 \%$ and in Downers Grove, $80 \%, \chi^{2}(1, N=281)=0.17, p>.05$.

\section{Effect of Law on Smoking Status}

As seen in Table II, there was a significant effect of the law on adolescents' smoking status in communities with regular enforcements versus

Table I. Participant's Demographics for Communities With and Without Enforcement

\begin{tabular}{ccc}
\hline Variable & $\begin{array}{c}\text { Regular Enforcement } \\
(n=124)\end{array}$ & $\begin{array}{c}\% \text { No-regular Enforcement } \\
(n=233)\end{array}$ \\
\hline Age & & \\
14 & 5.6 & 5.6 \\
15 & 31.5 & 31.8 \\
16 & 49.2 & 46.4 \\
17 & 13.7 & 16.3 \\
Grade & & \\
9 & 18.5 & 12.4 \\
10 & 62.9 & 66.1 \\
11 & 15.3 & 17.2 \\
12 & 3.2 & 4.3 \\
Gender & & \\
Male & 50.0 & 56.7 \\
Female & 50.0 & 43.3 \\
\hline
\end{tabular}


Table 1I. Effect of Law on Smoking Status for Communities with and Without Enforcement

\begin{tabular}{lcc}
\hline \multicolumn{1}{c}{ Status } & $\begin{array}{c}\text { \% Regular Enforcement } \\
(n=123)\end{array}$ & $\begin{array}{c}\text { \% Not-regular Enforcement } \\
(n=232)\end{array}$ \\
\hline Nonsmoker & 56.9 & 45.7 \\
Experimental & 15.4 & 22.4 \\
Social & 19.5 & 16.4 \\
Regular & 8.1 & 15.5 \\
\hline
\end{tabular}

those without regular enforcements, $\chi^{2}(3, N=355)=7.83, p<.05$. Woodridge had fewer smokers than Downers Grove (experimental, 15.6 vs. $22.7 \%$; social, 18.3 vs. $18.6 \%$; regular, 8.3 vs. $13.4 \%$ ) and more nonsmokers (57.8 vs. $45.3 \%)$, but this overall smoking status effect was not significant, $\chi^{2}(3, N=281)=5.27, p>.05$.

When a dichotomous variable was created in order to designate an adolescent as either a smoker or nonsmoker, there were significantly fewer smokers in regular enforcement communities than in communities without regular enforcement $(43.1$ vs. $54.3 \%), \chi^{2}(1, N=355)=4.05, p<.05$, and significantly fewer smokers in Woodridge in comparison to Downers Grove $(42.2$ vs. $54.7 \%) \chi^{2}(1, N=281)=4.14, p<.05$.

Of interest, the percentage of regular smokers in the two enforcement communities, Woodridge and Bolingbrook, was 8.3 and $7.1 \%$; whereas the percentage of regular smokers in the three communities without regular enforcement, Downers Grove, Westmont, and Darien, was 13.4, 31.3, and $18.2 \%$, respectively. For the state of Illinois, the average rate of regular smoking is $13.8 \%$. When a dichotomous variable was created composed of two categories, regular smokers versus not-regular smokers, there were significantly fewer regular smokers in communities with regular enforcements versus those without regular enforcements (8.1 vs. $15.5 \%), \chi^{2}(1$, $N=355)=3.89, p<.05$. Woodridge had fewer regular smokers than Downers Grove, and althought this effect was in the expected direction, it was not significant ( 8.3 vs. $13.4 \%), \chi^{2}(1, N=281)=1.73, p>.05$.

Participants who had smoked were asked about the quantity of cigarettes they smoked. There was no significant difference in the quantity of cigarettes smoked in the regular enforcement and no regular enforcement communities ( 3.0 vs. 2.4 cigarettes per day), $t(178)=-0.73, p>.05$, or when Woodridge was compared to Downers Grove (3.2 vs. 2.2 cigarettes per day), $t(139)=-1.04, p>.05$.

\section{Smokeless Tobacco}

Students were asked whether they had ever tried chewing or other smokeless tobacco. Significantly fewer adolescents in towns with enforce- 
ment versus towns without regular enforcement ( 8.7 vs. $16.7 \%$ ) tried chewing or other smokeless tobacco, $\chi^{2}(1, N=330)=4.05, p<.05$. In addition, significantly fewer adolescents in Woodridge compared to Downers Grove $(6.8$ vs. $17.7 \%)$ tried chewing or other smokeless tobacco, $\chi^{2}(1, N=261)=$ $6.41, p<.05$.

\section{Effect of the Law on Access to Cigarettes}

Participants were also asked what they thought the effects of this law might be. Smokers in communities with regular enforcement were more likely to state that it prevented or made it harder to get cigarettes $(69.8 \%)$ in comparison to smokers in communities without regular enforcement $(52 \%), \chi^{2}(1, N=178)=4.83, p<.05$. Smokers in Woodridge compared to Downers Grove were directionally (i.e., a nonsignificant effect in the expected direction) more likely to state that the law would prevent or make it more difficult for them to get cigarettes (67.4 vs. $52.7 \%), \chi^{2}(1, N=$ $139)=2.72, p>.05$. Directionally more of those smokers in communities with regular enforcement felt it was moderately difficult or difficult to get cigarettes than those in communities without regular enforcement (25.5 vs. $15 \%), \chi^{2}(2, N=160)=4.68, p>.05$, and directionally more in Woodridge felt that it was moderately difficult or difficult to get cigarettes than in Downers Grove (20 vs. $14.3 \%), \chi^{2}(2, N=124)=1.87, p>.05$.

When smokers were asked how many times they were successful out of 10 attempts to buy cigarettes, there were no significant differences between those in communities with or without regular enforcement $(M \mathrm{~s}=$ 6.9 vs. 7.3$), t(110)=0.51, p>.05$, or Woodridge versus Downers Grove $(M \mathrm{~s}=6.9$ vs. 7.2$), t(84)=0.49, p>.05$.

When smokers were asked where they obtained their cigarettes, significantly fewer obtained them in stores in regular enforcement communities compared to nonregular enforcement communities $(27.8 \mathrm{vs.} .46 .5 \%), \chi^{2}$ $(1, N=181)=5.47, p<.05$. At other sites (Table III) the differences

Table III. Sources of Obtaining Cigarettes

\begin{tabular}{lcc}
\hline & $\begin{array}{c}\text { \% Regular Enforcement } \\
(n=54)\end{array}$ & $\begin{array}{c}\text { \% Not-regular Enforcement } \\
(n=127)\end{array}$ \\
\hline Stores & 27.8 & 46.5 \\
Vending machines & 14.8 & 15.7 \\
Parents & 14.8 & 12.6 \\
Siblings & 18.5 & 15.7 \\
Friends (under age 17) & 50.0 & 49.6 \\
Friends (over age 17) & 53.7 & 50.4 \\
Other sources & 5.7 & 12.6 \\
\hline
\end{tabular}


were not significant. In comparisons of Woodridge versus Downers Grove, similar findings were found, except there was a nonsignificant effect in the expected direction for obtaining cigarettes in stores $(27.7$ vs. $44.2 \%), \chi^{2}(1$, $N=142)=3.63, p>.05$.

\section{Effect of Law on Where Smoking Occurs}

When comparing communities with regular enforcement versus those without regular enforcement, there were no significant differences in terms of where smoking occurred (Table IV). However, one significant difference emerged when comparing Woodridge and Downers Grove; smokers in the former community were less likely to smoke in video-game parlors (8.5 vs. $24.2 \%), \chi^{2}(1, N=142)=5.03, p<.05$.

\section{Age of Smoking Initiation}

There were no significant differences in the age of smoking initiation between the regular enforcement and the no-regular enforcement communities. The mean age of smoking initiation for communities with laws was 11.9 years, and without laws, 12.4 years, $t(164)=0.99, p>.05$. The mean ages in Woodridge and Downers Grove were 11.8 and 12.5 , respectively, $t(127)=1.35, p>.05$.

\section{Other Drugs}

Smokers were asked how many times they had used marijuana, alcohol, cocaine, other illegal drugs, and inhalants in the last 30 days, and there were

Table IV. Locations Where Smoking Occurs

\begin{tabular}{lcc}
\hline & $\begin{array}{c}\text { Regular Enforcement } \\
(n=54)\end{array}$ & $\begin{array}{c}\text { Not-regular Enforcement } \\
(n=127)\end{array}$ \\
\hline Parks & 31.5 & 37.0 \\
Home & 35.2 & 31.5 \\
Friend's home & 48.1 & 51.2 \\
A known hang-out & 27.8 & 34.6 \\
Shopping plaza & 20.4 & 22.8 \\
Fast food places & 29.6 & 29.9 \\
Video-game parlors & 11.1 & 18.9 \\
Other places & 27.8 & 40.2 \\
\hline
\end{tabular}


no significant differences between communities with regular enforcement versus those without regular enforcement. Similar findings were found when comparing Woodridge and Downers Grove. Among the entire sample, when we examined whether or not adolescents had used any of these drugs, those in towns with regular enforcement were not significantly less likely to use these drugs. This pattern was similar when comparing Woodridge with Downers Grove, except that for marijuana use, significantly less occurred in Woodridge (14.7 vs. $24.4 \%), \chi^{2}(1, N=281)=3.86, p<.05$.

When asked if any of their friends smoked cigarettes or used other drugs, there were no significant differences between communities with and without regular enforcement, $\chi^{2}(4, N=161)=2.02, p>.05$, or between Woodridge and Downers Grove, $\chi^{2}(4, N=125)=1.93, p>.05$. When asked how many times over the past year they had been approached by someone trying to give or sell them illegal drugs, those adolescents in communities with regular enforcement versus those without regular enforcement had significantly fewer occurrences $(M \mathrm{~s}=1.97$ vs. 5.48$), t(85)=$ $2.15, p<.05$, and there were directionally more occurrences in Downers Grove in comparison to Woodridge ( $M \mathrm{~s}=2.06$ vs. 4.07$), t(71)=1.71$, $p>.05$.

\section{DISCUSSION}

Similar findings emerged when comparing communities with and without regular enforcement, and comparing Woodridge with Downers Grove. About $80 \%$ of the adolescents said that they were aware of the Woodridge ordinance. Of most significance, $8.1 \%$ of those in regular enforcement communities were regular smokers versus $15.5 \%$ in no-regular enforcement communities. Among smokers, there were no differences in the overall quantity of cigarettes smoked. In addition, those in regular enforcement communities, compared to no-regular enforcement communities, used significantly less chewing tobacco or smokeless tobacco (8.7 vs. $16.7 \%$ ).

Even with enforcement, cigarettes continue to be available to most children. Although $69.8 \%$ of smokers in regular enforcement communities, versus $52 \%$ in no-regular enforcement communities, felt that the law prevented or made it harder to get cigarettes, even in regular enforcement communities only $25.5 \%$ said it was difficult or moderately difficult to get cigarettes. In addition, the smokers said they were successful in buying cigarettes about 7 out of every 10 times. However, in regular enforcement communities, $27.8 \%$ of smokers obtained cigarettes from stores, whereas in no-regular enforcement communities, $46.5 \%$ obtained cigarettes from stores. This is in contrast to the study by Rigotti et al. (1997), which found 
no reductions in tobacco use, but there were also no experimental versus control significant self-report differences over time regarding the percentage of youth who purchased tobacco.

It appears that the enforcement has had an effect on the number of children who smoke. As stated above, even in communities with regular enforcement, cigarettes are relatively easy to obtain, as there are many sources, including friends. Adolescents in regular enforcement communities could travel to neighboring towns without enforcement laws to purchase their cigarettes. Within regular enforcement communities, some stores continue to sell cigarettes to minors, and it is conceivable that the adolescents learn which stores continue to sell and then visit those stores more frequently. However, it is possible that when stores are less likely to be a source of cigarettes, this serves as a partial barrier to becoming a regular smoker for some adolescents in regular enforcement communities.

A somewhat unexpected finding was that in the last 30 days more Downers Grove adolescents had used marijuana than Woodridge adolescents. In addition, in no-regular enforcement communities, adolescents were more often approached by someone trying to give or sell them illegal drugs. It is possible that as a result of discouraging adolescents from becoming regular smokers, they become less likely to experiment with marijuana. In addition, those who are selling drugs might be less likely to engage in this activity in those communities that are perceived to be actively protecting youth as a result of their enforcement of anticigarette legislation. These findings are intriguing, and if these results are replicated in other settings, they have important public health implications.

There are several limitations in this study. First, the sample is small. The investigators had originally requested a larger sample from tenth grade, but official permission was only granted to collect data from a smaller sample. In addition, all children in the present study were attending school in a community with no regular enforcement of youth access-to-tobacco laws, so youths had easy access to tobacco products in the vicinity of the school they were attending. It is important to conduct follow-up investigations within communities that have regular enforcement and where the children are attending schools within those communities, and such studies by the authors are currently being undertaken.

Another limitation in the study is that prepoint data are not available for adolescents from the high school. It could be argued that parents and children within the two communities that enacted regular enforcement were more concerned about this issue, and this higher level of concern was a major factor that differentiated the communities with and without regular enforcement. While this possibility cannot be ruled out, pre-post data were available in the Woodridge's junior high school, during March 1989, before 
the ordinance to restrict tobacco sales to minors was passed, and in April 1991, almost 2 years after passage of the Woodridge ordinance, and the percentage of children describing themselves as regular smokers had decreased from 16 to $5 \%$, a percentage remarkably similar to regular smoking rates of the high school students from Woodridge 5 years later. These data support the contention that the ordinance was very likely the factor responsible for the decline in regular smoking. The results from the present study potentially have important public health implications, but until more controlled investigations are conducted, these findings need to be interpreted with caution as there continue to be possible alternative explanations for the outcomes.

From a community psychology perspective, this investigation supports the usefulness of establishing long-term commitments to social issues and settings. In 1988, a research team directed by the first author found about $80 \%$ of the stores in the Chicago land area that sold cigarettes did sell cigarettes to minors. These findings were publicized extensively by the media in the Chicago area (Jason, Ji, \& Anes, 1992). The state law prohibiting such sales was not effective, because a police officer first would have to observe a minor purchasing cigarettes, and then would need to take the store owner to the police station to process the complaint. An actual trial would then ensue-a time-intensive process for the police officer. It is not surprising that police officers rarely would take this type of action for this kind of offense.

Officer Talbot of Woodridge, a suburb of Chicago, contacted the first author after the above study had been publicized. Officer Talbot said that the Chief of Police had addressed this problem in his community by sending a letter to all merchants informing them that cigarettes were not to be sold to minors. The first author told the Officer that this letter would probably not change the merchants' behavior. Officer Talbot and the first author decided to work together to investigate the problem and its possible solutions. Minors were sent on a regular basis into all the community's stores to assess the extent to which cigarettes were sold to minors. When it was found that $70 \%$ of the stores sold to minors, legislation was developed to attack this problem.

Working with these data, Officer Talbot and the first author helped draft Woodridge's tobacco licensing and enforcement law, passed on May 1, 1989. Each merchant now needed to obtain a license to sell cigarettes. This feature of the law had several benefits. First, the money gained could be used to help identify cigarette vendors, and monitor repeatedly whether the stores were in compliance with the law. Second, the store owners were informed that if they were found violating the law a second time, their license to sell cigarettes would be suspended, resulting in a significant loss 
of income. In addition, all vending machines would need to be outfitted with a special lock, which could be opened only by an employee by pushing a button in view of the purchaser. In this way, minors would no longer have open access to cigarette machines. If store employees did sell cigarettes to minors, then the store license holders would be ticketed, but they would have no recourse to court appearances. In addition, notes from the minor's parent saying the purchase was for an adult would not be considered valid in the city, and the city law would take precedence over the state law that allowed for the acceptance of such notes. In addition, if minors were caught smoking, they would be issued a ticket entailing a $\$ 25$ fine.

In June 1989, after enforcement began, 33\% of these stores sold to minors. In accordance with Woodridge's law, first offense warnings were issued to these stores. The remaining stores that refused to sell cigarettes to the minors received police letters thanking them for refusing to sell. In August 1989, 36\% of the stores sold to minors. Half of these stores were repeat offenders from June. Those offenders received a one-day cigarette license suspension and a $\$ 400$ fine. No merchant contested the penalty. The first-offense stores were issued first-offense warnings. The rest of the stores received the police thank-you letter. At that point, the officials from the police department suggested that the problem had been mostly solved, and that regular enforcements were no longer needed. The first author disagreed with this recommendation, and suggested that if enforcements were not regularly performed, rates of illegal sales would soon increase once again. This recommendation was accepted, and enforcements have regularly occurred since then, and rates of sales of cigarettes to minors have remained at relatively low levels (Jason $e t$ al., 1996a).

The significant finding is that fewer merchants sold cigarettes to minors in Woodridge after passage and enforcement of the sales enforcement and vendor licensing provisions. Presampling education and awareness efforts (in the form of the police department's informative letter) were ineffective. Woodridge was the first community in the nation to document sustained reductions in illegal cigarette sales to minors as a result of legislation and enforcement. During all phases of the study, from the beginning to the end, the first author met with Officer Talbot and other police personnel to develop each step of this collaborative project. When baseline data indicated high levels of sales, that information was used to gain support for the legislation. After passage of the legislation, continued sampling indicated that the problem, although reduced, was still evident. These data helped convince our team of the need for continuous monitoring and feedback to the merchants.

Since passage of the legislation, Officer Talbot has been approached by dozens of communities interested in initiating similar campaigns. In 
addition, congressional hearings concerning cigarette sales to minors were convened in 1990, and Officer Talbot presented our study at these hearings. In the spring of 1990, Department of Health and Human Services Secretary Sullivan proposed a national legislative initiative to reduce cigarette sales to minors. Many of the major features of this proposed legislation were adopted from the study conducted in Woodridge. In 1992, the Synar Amendment was passed, and our work in Woodridge was used as a model that states around the country could follow in solving this problem. In addition, Officer Talbot became a leading authority on this topic, and has continued to consult with federal organizations and cities throughout the United States and Canada on ways of helping them reduce illegal sales of cigarettes to minors.

Smoking is the primary preventable cause of death, and yet 3,000 adolescents become smokers each day. The well-known health hazards of smoking make cigarettes very harmful to minors (Davis \& Jason, 1988; DiFranza et al., 1992). Most adult smokers begin this deadly habit when they are under the age of 18 , which is under the legal age for the purchase of cigarettes. The majority of adolescent smokers are able to purchase cigarettes even though laws prohibit the sale of cigarettes to minors. A number of educational campaigns have alerted merchants to the problem of minors' easy access to cigarettes. Although providing merchants with information does increase awareness of the issue, information alone will not decrease illegal cigarette sales. Perhaps the reason why merchants are passive about monitoring their cigarette sales to minors is the competition for adolescents' cigarette business. As one merchant told the Principal Investigator, "cigarette sales represent 15\% of my business, and if the minors didn't buy it here they'd buy it somewhere else." Since most merchants overlook the seriousness of this tissue, there is a need for new types of legislation that are effective in overcoming this serious health problem.

States are now required to enforce their laws in a manner that can reasonably be expected to reduce the extent to which tobacco products are available to underage youths. States determined not to be in compliance could lose up to $40 \%$ of their federal substance abuse funds. Because of this legislation, there are considerable activities at the state and local levels to reduce the sale of cigarettes to minors. A question frequently asked is whether reducing access to tobacco products will have any effects of adolescent smoking prevalence rates. Evidence from this study suggests that these types of laws might discourage some adolescents from beginning this habit. There is a need for further research to determine whether these results are replicated in other communities that have adopted these types of ordinances. 


\section{REFERENCES}

Altman, D. G., Rasenick-Douss, L., Foster, V., \& Tye (1991). Sustained effects of an educational program to reduce sales of cigarettes to minors. American Journal of Public Health, $81,891-893$.

Biglan, A., Henderson, J., Humphrey, D., Yasui, M., Whisman, R., Black, C., \& James, L. (1995). Mobilizing positive reinforcement to reduce youth access to tobacco. Tobacco Control, 4, 42-48.

Billows, B. D., Schnopp-Wyatt, D., \& Jason, L. A. (1995). Reducing the risk to minors participating in an urban intervention program [Letter to the editor]. Tobacco Control, 4, 92-93.

Centers for Disease Control. (1993). Cigarette Smoking-attributable mortality and years of life lost-United States, 1990. Morbidity and Mortality Weekly Report, 42, 645-649.

Centers for Disease Control. (1996). State Tobacco Control Highlights-1996 (CDC Publication No. 099-4895). Atlanta, GA: National Center for Chronic Disease Prevention and Health Promotion, Office on Smoking and Health.

Davis, R. M., \& Jason, L. A. (1988). The distribution of free cigarette samples to minors. American Journal of Preventive Medicine, 4, 21-26.

DiFranza, J. R., Carlson, R., \& Caisse, R. (1992). Reducing youth access to tobacco. Tobacco Control, 1, 58.

Feighery, M. S., Altman, D. G., \& Shaffer, M. A. (1991). The effects of combining education and enforcement to reduce tobacco sales to minors. Journal of the American Medical Association, 266, 3168-3171.

Forster, J. L., Komro, K. A., \& Wolfson, M. (1996). Survey of city ordinances and local enforcement regarding commercial availability of tobacco to minors in Minnesota, United States. Tobacco Control, 5, 46-51.

Hinds, M. W. (1992). Impact of a local ordinance banning tobacco sales to minors. Public Health Reports, 107, 355-358.

Jason, L. A., Billows, W. D., Schnopp-Wyatt, D. L., \& King, C. P. (1996a). Long-term findings from Woodridge in reducing illegal cigarette sales to older minors. Evaluation and the Health Professions, 19, 3-13.

Jason, L. A., Billows, W., Schnopp-Wyatt, D., \& King, C. (1996b). Reducing the illegal sales of cigarettes to minors: Analysis of alternative enforcement schedules. Journal of Applied Behavior Analysis, 29, 333-344.

Jason, L. A., Ji, P. Y., \& Anes, M. (1992). Assessing cigarette sales rates to minors. Evaluation and the Health Professions, 15, 375-384.

Jason, L. A., Ji, P. Y., Anes, M. D., \& Birkhead, S. H. (1991). Active enforcement of cigarette control laws in the prevention of cigarette sales to minors. Journal of the American Medical Association, 266, 3159-3161.

Johnston, L. D., O'Malley, P. M., \& Bachman, J. G. (1994). National Survey results on drug use from the monitoring the future study, 1975-1993, Volume I: Secondary school students (NIH Publication No. 94-3809). Rockville, MD: U.S. Department of Health and Human Services, Public Health Service.

Pierce, J. P., Fiore, M. C., Novotny, T. E., Hatziandreu, E. J., \& Davis, R. M. (1989). Trends in cigarette smoking in the United States, projections to the year 2000. Journal of the American Medical Association, 261, 65-65.

Radecki, T. E., \& Strohl, J. (1991). Survey of underage youth and alcohol purchase habits in 17 Midwest and Eastern states. Drug Free Youth News, 1, 1-8.

Radecki, T. E., \& Zdunich, C. D. (1993). Tobacco sales to minors in 97 US and Canadian communities. Tobacco Control, 2, 300-305.

Reducing minor's access to tobacco. (1990, Autumn). Tobacco and Youth Reporter, p. 17.

Rhodes, J. E., \& Jason, L. A. (1988). Preventing substance abuse among children and adolescents. New York: Pergamon. 
Rigotti, N. A., DiFranza, J. R., Chang, Y., Tisdale, T., Kemp, B., \& Singer, D. E. (1997). The effect of enforcing tobacco sales laws on youths' access to tobacco and smoking behavior. New England Journal of Medicine, vol. II, 337, 1044-1051.

Stanton, W. R., Mahalski, P. A., McGee, R., \& Silva, P. A. (1993). Reasons for smoking or not smoking in adolescence. Addictive Behavior, 18, 321-329.

U.S. Department of Health and Human Services. (1995). Regulations restricting the sale and distribution of cigarettes and smokeless tobacco products to protect children and adolescents; Proposed rule analysis regarding FDA's jurisdiction over nicotine-containing cigarettes and smokeless tobacco products; notice. Federal Register, 60, 41314-41787.

Xaverius, P. K., Billows, B. D., Jason, L. A., \& King, C. P. (1996). Research on the sales of smokeless tobacco to adolescents [Letter to the editor]. Tobacco Control, 5, 69-70. 